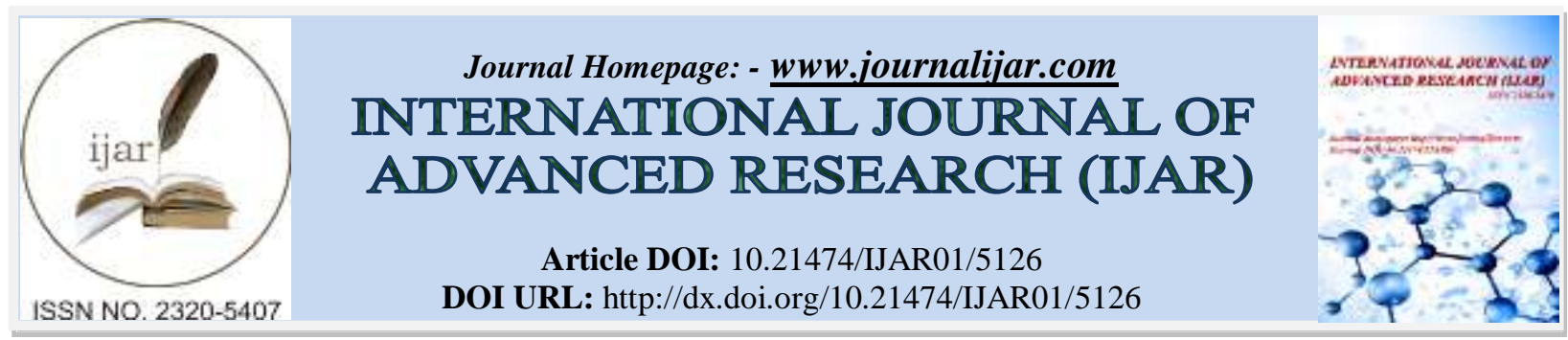

RESEARCH ARTICLE

\title{
MAXILLARY SINUS LIFT SURGERY TECHNIQUES: A LITERATURE REVIEW.
}

Jozely Francisca Mello Lima ${ }^{1}$, Jefferson David Melo de Matos ${ }^{2}$, Ítalo Kennedy Silva Santos ${ }^{2}$, Antonio Jackson Andrade Gonzaga de Oliveira ${ }^{3}$, John Eversong Lucena de Vasconcelos ${ }^{4}$, Lucas Villaça Zogheib ${ }^{5}$ and Daniel $^{2}$ Sartorelli de Castro6.

1. Professor of Dental Prosthetics, Department of Dentistry, Faculdade Paulo Picanço, Fortaleza - CE.

2. School of Dentistry, Centro Universitário UNILEÃO, Juazeiro do Norte - CE, Brazil.

3. Graduate in Letters - English Language, Universidade Regional do Cariri - URCA, Crato - CE, Brazil.

4. Professor of Oral Implantology, Department of Dentistry, Centro Caririense de Pós-Graduação CECAP, Juazeiro do Norte - CE, Brazil.

5. Professor of Dental Prosthetics, Department of Dentistry, Universidade de Fortaleza UNIFOR, Fortaleza - CE, Brazil.

6. Professor of Dental Prosthetics, Department of Dentistry, Centro Universitário Católica de Quixadá, Quixadá CE, Brazil.

\section{Manuscript Info}

Manuscript History

Received: 10 June 2017

Final Accepted: 12 July 2017

Published: August 2017

Key words:-

Sinus Lift; Atraumatic Technique;

Traumatic Technique, Maxillary Sinus.

\section{Abstract}

Introduction: Bone atrophy and pneumatization of the maxillary sinus resulting from tooth loss, associated with low bone density in the region, often provide inadequate quantity and quality for the installation of osseointegrated implants. Aim: In the present work, a literary review was carried out to identify and compare the main techniques of maxillary sinus surgery, commenting on the available graft materials. Methodology: A bibliographic search was carried out in the main PUBMED databases, in which works were published that were published from 1955 to 2017. 86 articles met the criteria for inclusion laboratory studies, case reports and systematic reviews as well as literature that were developed In the human species; In which they had done the lifting of the maxillary sinus with allocation of the grafting material. Results: In view of a careful research and tabulations of the respective articles, the result was that in many cases it is necessary to perform a surgical procedure to increase bone height, called maxillary sinus lift. The two techniques used for this purpose are the traumatic technique and the atraumatic technique, with or without bone graft. Conclusion: Maxillary sinus lift is a safe, reliable and successful surgical procedure, provided that the fundamental principles of the technique are strictly adhered to. The risks involved are small, with possible post-operative complications amenable to treatment through medication and / or surgical interventions.

Copy Right, IJAR, 2017,. All rights reserved.

\section{Introduction:-}

The process of repair in areas of dental extraction leads, as a consequence, to bone resorption due to the absence of stimuli generated by occlusal forces. When this situation remains, the osteoclastic activity becomes continuous, 
causing a decrease in the thickness of the border through the vestibular face and, later, a decrease in bone height, presenting different patterns of resorption in the maxilla and mandible ${ }^{1}$. Bone loss observed in the first three years after tooth extraction is $40 \%$ to $60 \%$, which may hamper or even render impossible the prosthetic rehabilitation of the area in question through the use of osseointegrable implants without previous surgical procedures for bone reconstruction ${ }^{2}$.

For installation of the implants, the remaining alveolar ridge should have adequate height and thickness, so that the implant ideally possesses $1.5 \mathrm{~mm}$ of bone tissue along its entire circumference. In contrast, the existence of a thin layer of bone per vestibular, for example, may lead to exposure of the metal due to bone resorption and soft tissue dehiscence. In this way, the ideal condition of implant placement involves a bisector between the buccal and palatal cortical laminae so that the occlusal load coming from the prosthesis installed on it impinges on its long axis ${ }^{3}$.

The literature has indicated the maxillary sinus lift procedure as an excellent treatment option for posterior maxillary edentulism and, when performed well, sinus graft procedures produce a significant amount of bone, allowing the installation of implants in an anatomical and proteic position proper. The variation of the technique to be used is defined by the quantity of bone remaining, its quality and surgical knowledge, and it is possible to use combinations of these in certain cases. In order to improve the bone height it is possible, besides the sinusal survey, to perform onlay grafts; However, this type of procedure usually does not offer noticeable changes ${ }^{4-6}$.

The use of autologous bone marrow derived from the iliac crest as graft material in the area; This technique, known as the Cadwell-Luc traumatic or access technique, is based on the creation of a lateral bony window to allow access to the interior of the maxillary sinus, elevation of Schneider's membrane and insertion of the graft, thus enabling bone height gain up to $12 \mathrm{~mm}$. Considering the installation of osseointegratable implants, it is performed in two surgical stages (one surgical procedure for sinus elevation and another for implant installation) or in only one stage, with the simultaneous installation of the implant at the moment of maxillary sinus lift ${ }^{7}$.

The maxillary sinus can also be elevated by a technique considered atraumatic, named in honor of its author (Summers, 1994). According to the current literature, this technique is more conservative and simplifies the technique of traumatic sinus elevation, reducing operative costs. However, the Summers technique generates less gain in bone height, limiting itself to a maximum of $4 \mathrm{~mm}^{8}$.

Several types of materials have been proposed for sinus grafting, including synthetic materials derived from bovine bone, human bone from "bone bank" and autogenous bone, which is considered the gold standard for maxillary sinus lift, since it is the More predictable material regarding bone augmentation procedures due to its properties of osteogenesis, osteoconduction and osteoinduction ${ }^{9}$.

Based on the above, it is objectified with this literature review to clarify the techniques of maxillary sinus survey, considering some options for grafting materials; As well as its applications in the clinical routine of the dental surgeon.

\section{Methodology:-}

A bibliographic search was conducted in the main PUBMED database (www.pubmed.gov), which collected works that were published from 1955 to 2017. It included laboratory studies, case reports and systematic reviews as well as literature that Were developed in the human species, and, therefore, articles that did not deal with the rehabilitative maneuvers of maxillary sinus removal were excluded, even if they did not use grafts.

Through the bibliographic research, 86 articles were selected, all of which were extracted from PUBMED (www.pubmed.gov), as previously reported (FIGURE.1 and GRAPH.1). The following titles of specific medical subjects and keywords were used: ([Sinus Lift [MeSH Terms]), Atraumatic Technique ([MeSH Terms]), Traumatic Technique ([MeSH Terms]), Maxillary Sinus ([MeSH Terms]). 
Figure 1:- Flowchart of the criterion of inclusion of articles.
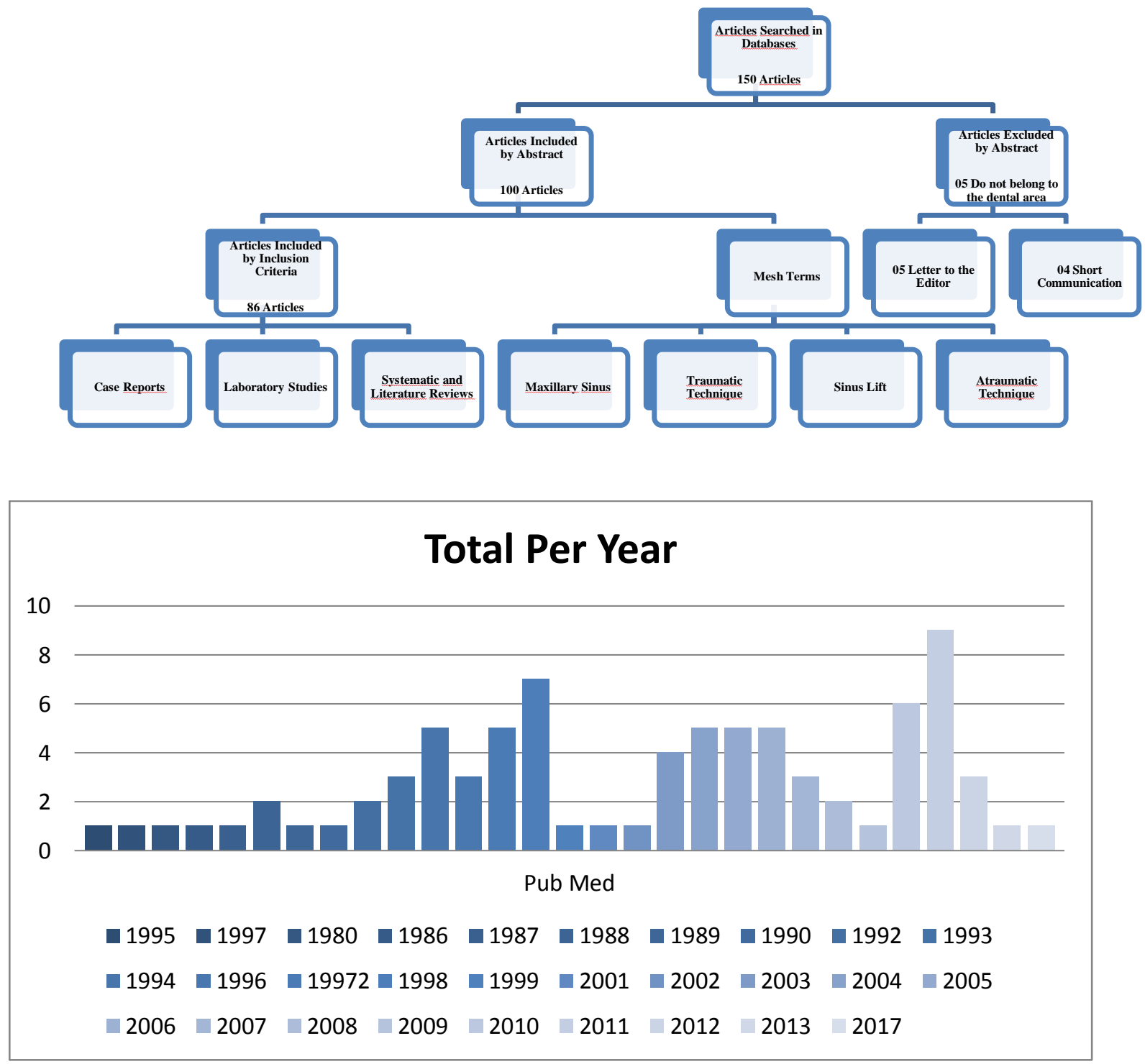

Graph 1:- Cumulative Graph.

\section{Results:-}

Through the review, all the papers presented the approach of the maneuver of lifting the sinus either by traumatic or atraumatic form with allocation of grafting material or without it. In the understanding that the techniques used can be atraumatic, through the Summers technique with or without bone graft, and traumatic, through the access of Cadwell-Luc with simultaneous installation of implants or two surgical stages. The variation of the technique to be used is defined by the quantity of bone remaining, its quality and surgical knowledge, and it is possible to use combinations of these in certain cases.

Several materials for sinus grafting have been studied since the first description of the maxillary sinus procedure with autologous bone marrow. In 1996, the Consensus Conference on Bone Graft in the Maxillary Sinus reviewed the available data and concluded that autogenous, alloplastic and xenogene grafts, isolated or in combination, may be effective in this surgical procedure, and conclude that the simultaneous traumatic technique consists of a modality Highly predictive and effective therapy for the rehabilitation of the posterior maxilla. 
Comparing different techniques of maxillary sinus sampling and grafting materials, it was possible to demonstrate that there were no statistically significant differences when compared with panoramic radiographs of the late and immediate implants, or when histomorphometrically comparing the grafting materials used. Thus, it can be observed that both the implantation techniques available (late or immediate) and the grafting materials studied can be used safely for lifting the maxillary sinus.

The material considered "gold standard", showing high success rates and predictable results, is the autogenous bone, which can be obtained from different regions of the oral cavity, such as mandibular symphysis, maxillary tuberosity and edentulous border. However, its disadvantages should be considered when indications for sinus grafting, including limitations on the amount of available material, associated morbidity and tendency to resorption. These characteristics have motivated the search for other more advantageous materials that do not compromise, however, its main advantage, which consists in the shorter period of time necessary to the bone regeneration. The simultaneous installation of osseointegrable implants was studied using several extraoral sources of autogenous bone for sinus grafting, such as iliac crest, iliac crest or sinus and parietal bone, and the latter allowed the authors to suggest that the breast lift technique Maxillary bone graft by autologous parietal bone graft is reliable, and it is possible to successfully place immediate implants even in situations of severe bone height deficiency $(<4 \mathrm{~mm})$.

The addition of autogenous bone scrapings to bovine mineral bone (BBM) in a ratio of 1: 4, compared to BBM alone did not significantly increase the formation of new bone after 4 months of maxillary sinus removal. On the other hand, reviewing the existing literature on the hypothesis that there is no difference in bone formation in sinuses grafted with Bio-Oss or Bio-Oss associated with autogenous bone as a graft for maxillary sinus lift and demonstrated that the volumetric stability of the graft improved significantly with an increase in the proportion of Bio-Oss, which was influenced by a higher percentage of Bio-Oss added to the autogenous graft. The use of porous hydroxyapatite as a graft in maxillary sinus surgery simplified the surgery as it allowed it to be performed in the office and under local anesthesia, in addition to reducing costs, surgical time and morbidity. In this way, more and more bone substitutes, alone or in combination with autogenous bone, for this type of surgical procedure, mainly because they are found in unlimited quantity.

It has been successfully demonstrated in the literature the induction of formation of new bone in the maxillary sinus only by means of the surgical procedure of lifting the sinus membrane, without the use of any grafting material. A true osteogenic potential is associated with the Schneider's membrane, which contributes intensely to the success of maxillary sinus lift procedures. Recent studies have shown promising results in the maxillary sinus lift with the use of stem cells, indicating a new area to be explored. Trunk-mesenchymal cells, when used in combination with bovine bone mineral for sinusal survey, may be a viable alternative when compared to other currently available grafting materials.

\section{Discussion:-}

The absence of sufficient bone volume in the posterior maxillary region can generate several complications for oral rehabilitation through osseointegrable implants, especially the installation of anatomically implanted and proteanically unfavorable implants. In addition, severe reabsorption of the posterior maxilla region may also lead to changes in chewing, swallowing, speech, and consequently leading to psychological disturbances ${ }^{10}$.

This situation, commonly found, occurs due to the bone remodeling pattern of the posterior maxilla, which loses bone faster than any other region, resulting in vertical and horizontal resorption of the alveolar bone due to lack of stimulation by the fibers of the periodontal ligament. The absence of maxillary molars leads to osteoclastic activity on Schneider's membrane, causing bone reabsorption of the sinus in a few months. In addition, periodontal disease causes severe bone resorption. The base of the maxillary sinus tends to expand inferiorly, decreasing the remaining bone height in edentulous patients for a long time, hindering or even preventing the installation of osseointegrated implants ${ }^{11}$. The creation of three-dimensional models of the maxillary sinus from data obtained from computed tomography is able to facilitate the preoperative plan of sinus augmentation and simultaneous fixation of implants with adequate precision at the appropriate site. This assertion was made at the end of the 1990s, after experiments with computerized tomographic exams and subsequent acrylic modeling in three patients previously indicated for such surgical procedure ${ }^{12}$.

Panoramic radiographs of the maxillary sinus, as well as possible CT scans are necessary to determine available alveolar bone height, location of possible septa and exact location of the surgical approach, and it is also important 
to verify the presence of diseases such as acute sinusitis and polyps, tumors or Cysts in the antral cavity ${ }^{13}$. The collection of a complete medical history and clinical evaluation of the patient, especially the maxillary sinus. Sinusitis is one of the most commonly neglected diseases in clinical practice, and a potential infection in the region of the maxillary sinuses can result in extremely severe complications. Acute, allergic or chronic maxillary sinusitis can be diagnosed through the patient's history and / or clinical examination ${ }^{14}$.

Due to the procedures for evaluation of quantity and quality of bone tissue prior to implant installation surgery, the need for more precise radiographic examinations was developed and capable of providing the necessary information to the professional for the correct planning, precision of the surgical procedure and Postoperative control. In this sense, periapical, panoramic, postero-anterior maxillary sinus x-rays and computerized tomographies help to know the dimensions of the alveolar bone, indicate if there are septa in the sinus, show the exact location of the surgical access, as well as verify the presence of Sinusitis, residual roots, polyps or retention cysts in the area in question ${ }^{15}$.

The information obtained with the clinical and radiographic examination determines the diagnosis, prognosis and appropriate treatment; Thus, the indication of the maxillary sinus lift varies according to the surgical technique chosen. The radiography indicated for such analysis is the panoramic view that, although it has an average magnification of $25 \%$, allows to perform measurements of the remaining bone height. Computed tomography, in turn, provides accurate information on the thickness of available alveolar bone and the actual distance from the bone crest to the anatomical areas of interest, thus providing the clearest image for the location of septa within the sinus ${ }^{16}$.

Contraindications for maxillary sinus surgery include all medical conditions and medications that prevent the placement of implants. In this sense, the patient's medical history should be investigated for systemic or sinus problems or diseases, factors that may complicate or contraindicate the procedure. Such alterations to be investigated include presence of sinus pathology, including acute sinusitis, polyp and / or cyst or antral tumor, use of inhaled steroids and cocaine dependence ${ }^{17}$.

\section{Maxillary Sinus Lift Technique:-}

In 1994, a less invasive and relatively simpler technique for maxillary sinus elevation was described when compared to the classic described traumatic technique described. Also called the osteotome technique, it is able to maintain a greater amount of bone existing in the maxilla by elevating the floor, periosteum and sinus membrane with minimal trauma and without direct contact between the membrane and surgical instruments ${ }^{18}$. Its execution is possible due to the low bone density in the posterior region of the maxilla (bones type III or IV), and it can be indicated only when the presence of bony remnants of 5 to $6 \mathrm{~mm}$, since it can elevate the floor in a maximum of $4 \mathrm{~mm}$. As the osteotomes have a cylindrical shape with the concave cavity, the bone remains on the active tip of the instrument during its displacement in the apical direction; Additionally, the pressure generated during the use of these instruments allows the compression of the bone layers around their region of action, thus forming a denser interface between bone and implant. It is known that this bone compaction increases the bone density locally, which favors the immediate implantation of the implant, however it is necessary to keep in mind that the total success of the procedure is also dependent on the amount of bone pre-existing between the crest of the alveolar ridge And the maxillary sinus floor, since this point is crucial for the primary stabilization of the implant ${ }^{19}$.

The Summers technique can be performed associated or not with bone grafts. For both procedures, osteotomes are used which, with a gradual increase in size, are introduced sequentially to expand the alveolus and elevate the Schneider membrane. In this way, the bone is compressed at each insertion of a larger osteotome, being pushed laterally and apically, thus improving the bone density of the posterior region of the maxilla. With the sinus floor already elevated, the techniques differ. While the atraumatic technique of maxillary sinus lift without bone graft is performed with the choice and insertion of the implant, according to the usual procedures recommended by Implantodontia, the atraumatic technique of maxillary sinus lift with bone graft gains a further step: The broader osteotome used is reinserted into the cavity containing the graft material positioned at its active tip, pressing and raising the sinus membrane, so as to deposit the material to be grafted under it; Only then when the desired height was obtained and the graft positioned, proceed with the implant installation ${ }^{21}$.

The bone mixture to be used as a graft should be composed of $25 \%$ autogenous bone associated with $75 \%$ hydroxyapatite. However, the current literature indicates various materials to be used for this purpose, alone or in combination. Immediate installation of implants in areas of less than $6 \mathrm{~mm}$ bone would be risky or even impossible due to possible lack of primary stability. In these cases, the so-called 'development of future sites' technique is 
indicated, in which the bone is refined in the edentulous area and compacted externally to the buccal environment for use as a graft through the technique of atraumatic maxillary sinus elevation with bone graft. This technique has been shown to be interesting because, due to the presence of live cells and bone proteins in the trephined bone block, graft maturation occurs more rapidly, making the healing time shorter when compared to the traumatic sinus lift technique ${ }^{22}$.

The osteotome technique was modified in order to use such instruments with the conical rather than concave tip, which theoretically would allow more efficient and less traumatic lateral condensation to the bone. However, when it comes to elevation of the maxillary sinus floor, increased pressure at the tip of the osteotome may increase the risk of perforation of the sinus membrane. Thus, this technique should be indicated in cases where there is a wide thickness of the alveolar crest $(>7 \mathrm{~mm})$, with a subsinusal height equal to or greater than $5 \mathrm{~mm}$, and an adequate space for prosthesis. Its indication is independent of local bone density, so much so that many authors have advocated the use of drill bits to prepare the surgical site in cases of high density bone ${ }^{23-25}$. In 1998 a sinus removal technique was described immediately after extraction of the superior molar, using, for this purpose, trephine drill in association with osteotomes and guided bone regeneration. By performing breast lift together with the implant installation immediately after the extraction, the bone resorption process inherent to tooth loss would be decelerated, thus allowing a clinical result with better function and esthetics. Such a technique can only be performed if the tooth to be extracted does not present any outbreak of infection or contamination ${ }^{26}$.

In 2003, a new endoscopic technique of sinus lift was proposed through a small osteotomy in the antero-inferior wall of the same. Despite requiring special surgical training and specific materials, this technique, similar to the Summers technique, has been shown to have several advantages, such as minimally invasive access, preservation of vital bone and blood supply ${ }^{27}$. The conventional techniques of breast lift are well accepted and have very favorable results regarding the rehabilitation of the posterior atrophic maxilla. However, in cases of anatomical limitations such as regions between two teeth, for example, the sinus lift procedure may become complicated and risky ${ }^{28}$. Sinus membrane perforation is a common complication during the breast lift procedure, but the risk and rate of this perforation is lower in the osteotome technique than in those reported for the traumatic technique. Even when compared to the traumatic technique, the Summers technique has as main disadvantage lower gain in height, about $3.5 \mathrm{~mm}$ to $5 \mathrm{~mm}$ against $10 \mathrm{~mm}$ to $12 \mathrm{~mm}$ through Cadwell-Luc Access ${ }^{29}$.

\section{Traumatic Maxillary Sinus Surgery Technique:-}

It is considered a standard procedure for maxillary sinus lift, the trauma technique being indicated in cases with less than $5 \mathrm{~mm}$ and more than $2 \mathrm{~mm}$ of remaining bone located between the crest of the alveolar ridge and the sinus floor. For its execution, the best option of local anesthesia is the posterior and anterior superior alveolar nerve block, in addition to palatine infiltrative anesthesia. The incision should be performed on the alveolar ridge from the palatine tuberosity to the canine pillar, referring to the anterior portion of the maxillary sinus, performing at this point a relaxing vertical incision to the bottom of the buccal groove ${ }^{30}$.

Soft tissue detachment is then performed for total flap preparation and beginning of choice osteotomy. Under copious irrigation and with spherical diamond drill $n^{\circ} 6$ or $n^{\circ} 8$, a bone window is created with dimensions that depend on individual factors in each case to be rehabilitated, such as prosthetic area to be recomposed, presence or not of adjacent teeth and anatomy of the sinus, Including the presence or absence of bone septa ${ }^{31}$. This osteotomy should be performed carefully to avoid perforation of the Schneider's membrane, which becomes visible as the vestibular bone becomes thinner, characterizing a grayish or even purple-blue line in the wear area; It is possible to verify the integrity of the membrane at the end of the osteotomy from the respiratory movements of the patient, since the bone window moves accordingly if the membrane has not been perforated (Valsalva maneuver). If there is perforation, it is repaired and the graft placed or not according to the extent of the rupture; If no perforation is found, the graft material is then placed into the cavity for complete filling ${ }^{32}$.

The osteotomy required for the creation of the bone window, regardless of the chosen wear technique, should always be started from the inferro-horizontal cut located $3 \mathrm{~mm}$ above the alveolar crest, proceeding by the vertical-anterovertical cut and, finally, Or upper-horizontal. There are basically three types of osteotomy that can be performed for Cadwell-luc access to the maxillary sinus: osteotomy, hinge-type, elevation, and complete. In bone hinge wear, horizontal upper osteotomy is performed punctually instead of continuous line, which causes the opening of the bone window to be performed through a green branch fracture, allowing its upper part to be slightly attached to the jaw. For osteotomy by elevation, wear is done with brushing movements in all cuts to make the bone window and, 
instead of performing a green branch fracture, the bone remnant is pushed into the sinus; In this way, the risk of perforation of the membrane is lower, since it is completely free, which also allows for the elevation of the bone remnant at a level above where the most superior osteotomy was performed. On the other hand, complete osteotomy is best indicated in cases in which alveolar resorption is already very advanced, the zygomatic process of the maxilla is very close to the alveolar ridge and, due to this angulation, the visual access may be compromised; Its execution is similar to osteotomy by elevation, except that, at the end of the bone wear and before starting the sinus membrane detachment, the entire bone is removed from the wall of the maxilla that was inside the quadrilateral with aid Of a straight curette. This technique has as a disadvantage the greater possibility of causing perforation of the membrane during the time of bone curettage of the quadrilateral, but has the advantage of better visualization to proceed with greater safety during the displacement of the same in the later stages ${ }^{33}$.

One of the possible complications involved in this type of surgical procedure is the presence of septum in the maxillary sinus, found in approximately $31 \%$ of patients, most commonly in edentulous atrophic maxilla. The presence of the septum hinders the detachment of the membrane, which increases the chances of perforation. One way to identify and locate the septum is through careful radiographic analysis or, more clearly visualized, through a computerized tomography performed prior to surgery ${ }^{34}$.

The traumatic sinus lift technique can be performed in two surgical stages (first for maxillary sinus lift and posteriorly for osseointegratable implant) or simultaneously with the implant (a surgical stage). When in two stages, the treatment time becomes longer, it is necessary to wait for the maturation of the graft (about 6 months) and osseointegration of the implant later installed. For simultaneous implantation of the implant it is necessary that there is sufficient bone height to promote stability and primary fixation of the implant (at least $5 \mathrm{~mm}$ between the crest of the alveolar ridge and the sinus floor); Its main advantage is the reduction of the time between sinus grafting and the placement of implants, thus eliminating a surgical phase ${ }^{35}$.

Modification of the technique of surgical elevation of the inferior wall of the sinus due to a septum in the maxillary antrum. The maxillary septum can divide the sinus into two separate compartments and, in these cases, opening only one cavity does not provide adequate access to the bone graft, in addition to hampering the detachment of the membrane without perforations, since this is generally firmly adhered to such bone structure. The authors reported that the bone is usually very thin before the presence of a septum, revealing itself as a vertical opacity contrasting with dark translucency of the maxillary sinus when exposed to transillumination. Once identified, its positioning should be correlated with the preoperative radiography, determining the exact location of the two trapezoidal bony windows, one on each side of the septum, which should be kept intact. The Schneiderian membrane should be elevated in both windows and, after the bone graft is placed and compacted, a regenerative membrane should be positioned at the entrance of the bone windows and the flap repositioned and sutured with non-resorbable wire ${ }^{36}$.

\section{Grafting materials in the maxillary sinus:-}

A safe and predictable bone graft mix for the maxillary sinus lift procedure consisting of autogenous cortical bone graft, bovine bone and platelet rich plasma (PRP). A total of 263 implants (171 Astra Tech and 92 Microdent) were placed simultaneously or late and all stores evaluated clinically and radiographically 24 months after their prosthetic loading. Biopsies were taken from 16 sites at the time of implant placement. The $100 \%$ success rate of the implants was determined after 24 months of installation of the prostheses on them. Only two implants (Microdent) failed before loading, which translates into a success rate of $99 \%$ of implants. No statistically significant difference was found between simultaneous and late implant placement. Image processing revealed $34 \pm 6.34 \%$ of vital bone, 49.6 $\pm 6.04 \%$ of connective tissue and $16.4 \pm 3.23 \%$ of Bio-Oss particles; However, the histomorphometric analysis showed that the bovine bone was incorporated into the neoformed bone. From the results found, the authors could conclude that autogenous cortical bone graft, bovine bone and PRP blend can be successfully used for the maxillary sinus lift ${ }^{37}$.

The mixture of autogenous bone scrapings with bovine mineral bone (BBM) at a ratio of $1: 4$, as compared to BBM alone, would have no significant effect on new bone formation 4 months after maxillary sinus lift. To provide this hypothesis, the authors recruited 24 patients with bone height less than $5 \mathrm{~mm}$ in the posterior maxilla area and randomly divided them into 2 treatment groups. 12 maxillary sinuses were grafted with a mixture of BBM and autologous cortical bone collected from the lateral wall of the maxillary sinus by a bone scraper and the remaining 12 breasts grafted with BBM alone. After 4 months of surgery, the bone formation in the treated sites was evaluated through bone scintigraphy, as well as histological and histomorphometric analyzes from the biopsies collected at the 
time of implant placement. After due statistical analysis, the results showed that new bone formation detectable by scintigraphy did not differ between groups $(\mathrm{P}>0.05)$; Histologically, grafted bovine bone underwent osteoclast action at sites with or without autogenous bone; Histomorphometrically, the difference between the percentages of newly formed bone in the breast grafts with the graft mix (25.73\%) and only BBM (24.19\%) was not statistically significant $(\mathrm{P}>0.05)$. Thus, the authors concluded that the addition of autogenous bone grazes to the bovine mineral bone at a ratio of 1: 4, compared to BBM alone, did not significantly increase the formation of new bone after 4 months of maxillary sinus removal ${ }^{38}$.

Regarding the hypothesis that there is no difference in bone formation in sinuses grafted with Bio-Oss or Bio-Oss associated with autogenous bone as a graft for maxillary sinus lift through the side window technique tested in animals. The systematic review of the literature included animal studies published in English from January 1,1990 to June 1, 2010; 879 titers were obtained and 14 studies met the inclusion criteria, which demonstrated that the volumetric stability of the graft improved significantly with increasing ratio of Bio-Oss. Bone regeneration, boneimplant contact area, biomechanical implant values and Bio-Oss biodegradation after sinus lift surgery using only Bio-Oss or Bio-Oss associated with autogenous bone were never compared within the same study in animals. Thus, the hypothesis that there is no difference between the use of Bio-Oss and Bio-Oss associated with autogenous bone as a matter of grafting to the maxillary sinus cannot be confirmed or denied based on existing studies in animals ${ }^{39}$.

In studying human bone morphogenetic protein (rhBMP-2), some researchers have stated that its use in an absorbable collagen sponge (ACS) is capable of significantly inducing bone formation in various configurations, including from the maxillary sinus floor. In this way, the authors compared the local bone formation and osseointegration of implants simultaneously installed to the sinus graft using rhBMP-2 / ACS and autogenous bone originating from the iliac crest. 5 minipigs, using rhBMP-2 $(0.43 \mathrm{mg} / \mathrm{ml}) /$ ACS and autologous graft on the contralateral side, were submitted to the bilateral sinusal procedure. In each of the breasts approached were installed 2 implants with $12 \mathrm{~mm}$ in length. Surgical sites were sutured in layers and biopsies were collected for histomorphometric analysis after 8 weeks. The results obtained determined that the use of rhBMP-2 / ACS induced bone formation with significantly higher and consistent quality compared to iliac crest graft, with mean bone density from $51.9 \pm 3 \%$ to $32.9 \pm 2,5 \%$ in the autogenous bone $(\mathrm{P}=0.01)$. Thus, the authors concluded that for maxillary sinus surgeries, the use of rhBMP-2 / ACS determines the formation of superior bone in comparison to iliac crest graft, and this material may have to be considered the new standard for this type of surgical procedure ${ }^{40}$.

\begin{abstract}
Allogenic bone:-
In a histological, histomorphometric and radiographic study of a new bone type for maxillary sinus grafting. Such a bone substitute differs from other existing allogeneic grafts due to its cryopreservation method. Histological analyzes of bone biopsies obtained at the moment of implant installation revealed a neoformed bone with a well organized lamellar structure and some remaining particles in close contact with this bone. The histomorphometric results showed a mean formation of new bone in 31.8\%. Linear radiographic data demonstrated a percentage of graft resorption of $8.49 \pm 6.77 \%$ after 6 months of surgery. From the obtained data, the authors could conclude that this new bone substitute can be successfully used in procedures of maxillary sinus survey, and its promising results are an incentive to further research of this irradiated bone material preserved in oral and maxillofacial reconstruction ${ }^{41}$.
\end{abstract}

\title{
Xenogen bone:-
}

In 1998, the inorganic bovine bone matrix (Osteograf®) was used to lift 113 maxillary sinuses in association with autogenous bone or lyophilized demineralized bone, resulting in a success rate of installed implants of $98.2 \%$. The percentage of vital bone increased over time after a 3-year observation period and was significantly higher when used in combination with autogenous bone or with polytetrafluoroethylene membrane protecting the sinus cavity ${ }^{42}$. One of the first publications investigating the bone reaction to mineralized bovine bone used for maxillary sinus removal was performed when the histological results were monitored from 6 months to 4 years after maxillary sinus removal with the material in 20 patients. The histological analysis performed on the biopsies obtained showed that the BioOss particles were surrounded by compact and mature bone for the most part. No gaps were observed at the interface between the particles and the newly formed bone. In some slides, it was possible to observe Harvesian channels, small capillaries, mesenchymal cells and osteoblasts. In the specimens obtained at a longer follow-up period (18 months to 4 years), it was also possible to observe osteoclastic reabsorption of the remaining particles, surrounded by neoformed bone, suggesting that the reabsorption of the material is slow in humans. $\mathrm{O}$ material foi considerado, a partir dos resultados, como biocompatível e osseocondutor, podendo ser usado como substituto ósseo nos procedimentos de levantamento de seio maxilar ${ }^{43}$. 


\begin{abstract}
Alloplastic Materials:-
The porous hydroxyapatite as a graft material in maxillary sinuses, demonstrating simplification in the surgery as the material allowed it to be performed in the office and under local anesthesia, in addition to reducing costs, surgical time and morbidity. Thus, other authors (Haas et al, 2002), through their studies over the years, have increasingly recommended bone substitutes, alone or in combination with autogenous bone, for sinus lift procedures, mainly because they are found in unlimited quantity ${ }^{44}$.
\end{abstract}

\title{
Stem cells:-
}

The stem-mesenchymal cells (CTMs) have a high potential for in vitro expansion, self-renewal capacity and immunomodulatory properties. CTMs can be isolated from different tissues, such as bone marrow, peripheral blood, umbilical cord blood, adult connective tissue, placenta, dental pulp. Its osteogenic plasticity is very useful in the field of reconstructive bone surgery, including oral surgery, orthopedic surgery, maxillofacial surgery and implantology ${ }^{45-50}$. In these specialties, many patients require the infusion of mesenchymal cells for bone regeneration, either alone or with osteo-inducers. Mesenchymal stem cells, when combined with porous materials such as the combination of hydroxyapatite and calcium phosphate (HA / TCP) composed of 40\% HA and 60\% TCP, have been shown to be effective in inducing bone formation in large defects. HA / TCP particles are becoming an increasingly important matrix for bone reconstruction and tissue engineering. Since its mineral content, density and three-dimensional properties are especially suitable for the microenvironment of the bone, the radiographic evaluation of new bone formation is difficult ${ }^{51-57}$.

Maxillary sinus lift has been demonstrated as an effective way to increase vertical bone height to achieve a primary stability of the implants in the posterior area of the reabsorbed jaw. To avoid the complications that accompany the autogenous grafts, the professionals of the area use more and more synthetic bone substitutes. Bone marrow is the usual source of adult stem-mesenchymal cells for hematopoietic stem cell transplantation and cell therapy; However, the collection of these cells is part of a surgical procedure that generally requires general anesthesia, increasing morbidity for the patient. In this sense, there is currently a great interest in finding other sources of stem cells ${ }^{58-66}$. For dental surgeons, obtaining stem cells from dental tissues is a simple and minimally invasive procedure; (DPSCs) are multipotent, possessing high capacity for self-renewal and expansion in vitro, and can differentiate into cells of all germ layers, including ectoderm (nerve cells), mesoderm (myocytes, osteoblasts, chondrocytes , Adipocytes and cardiomyocytes) and endoderm (hepatic cells). Dental pulp stem cells may be ideal candidates for reconstructive therapy as they are devoid of the ethical problems associated with other types of stem ce ${ }^{66-79}$.

\section{Sinus Surgery and Simultaneous Installation of Implants:-}

According to the remaining bone conditions, the surgeon can use two different techniques for maxillary sinus lift and implant placement. The simultaneous procedure, or in a surgical stage, determines the installation of the implants at the same surgical time as the sinus lift, whereas in the two-stage procedure it is necessary to wait for the maturation phase of the grafted material in the sinus for the subsequent installation of the implants ${ }^{80-83}$. The great advantages of the procedure in a surgical stage are the reduction of healing time and the lower risk of reabsorption of the grafted bone. For insertion of the implant together with the graft of the sinus, however, there must be a minimum bone remnant of $5 \mathrm{~mm}$ between the bone crest and the inferior sinus wall ${ }^{84-86}$.

\section{Conclusion:-}

\section{It can be concluded from this study that:-}

Maxillary sinus lift is a safe, reliable and successful surgical procedure, provided that the fundamental principles of the technique are strictly adhered to. The risks involved are small, with possible post-operative complications amenable to treatment through medication and / or surgical interventions. Different materials have been used for sinus graft, such as various types of synthetic materials derived from bovine bone, human bone from "bone bank" and autogenous bone, which is considered the "gold standard" for maxillary sinus The most predictable material for bone augmentation procedures due to its high osteoconductivity and low dependence on bone migration from the sinus wall. Recent studies have focused on the use of stem cells in combination with various types of grafting materials for sinus removal, showing extremely promising results, but requiring more studies for their consecration.

\section{Conflict of Interests:-}

The authors declare they do not have any conflict of interests. 


\section{References:-}

1. Betts NJ, Miloro M. Modification of the sinus lift procedure for septa in the maxillary antrum. J Oral Maxillofac Surg. 1994, 52:332-3.

2. Blomqvist JE, Alberius P, Isaksson S. Two-stage maxillary sinus reconstruction with endosseous implants: a prospective study. Int J Oral Maxillofac Implants. 1998, 13(6):758-66.

3. Boyne PJ, James R. Grafting of the maxillary floor with autogenous marrow and bone. J Oral Surg. 1980, 38:613-616.

4. Cawood JI, Howell RA. A classification of the edentulous jaws. Int J Oral Maxillofac Surg. 1988, 17(4):232-6.

5. Chackartchi T. Sinus floor augmentation using large $(1-2 \mathrm{~mm})$ or small $(0.25-1 \mathrm{~mm})$ bovine bone mineral particles: a prospective, intra-individual controlled clinical, micro-computerized tomography and histomorphometric study.Clin Oral Implants Res. 2011 22(5):473-80.

6. Chanavaz M. Maxillary sinus: anatomy, physiology, surgery,and bone grafting related to implantology: eleven years of surgical experience (1979-1990). J Oral Implantol. 1990, 16:199-209.

7. Chiapasco M, Ronchi P. Sinus lift and endosseous implants: preliminary, surgical and prosthetic results. Eur J Prosthodont Restor Dent. 1994, 3(1):15-21.

8. Daelemans P, Hermans M, Godet F, Malevez C. Autologous bone graft to augment the maxxilary sinus in conjunction with immediate endosseous implants: a retrospective study up to 5 years. Int J Periodontics Restorative Dent.1997, 17(1):27-39.

9. Davarpanah M. The modified osteotome technique. Int J Periodontics Restorative Dent. 2001, 21(6):599-607.

10. De Melo WM. Autogenous bone combined with anorganic bovine bone for maxillary sinus augmentation: analysis of the osteogenic potential of cells derived from the donor and the grafted sites. Clin Oral Implants Res, Jan 7, 2013.

11. Del Fabbro M, Testori T, Francetti L, Taschieri S, Weinstein R. Systematic review of survival rates for immediately loaded dental implants. Int J Periodontics Restorative Dent. 2006, (3):249-63.

12. Engelke W, Schwarzwäller W, Behnsen A, Jacobs HG. Subantroscopic laterobasal sinus floor augmentation (SALSA): an up-to-5-year clinical study. Int J Maxillofac Implants. 2003, 18(1):135-43.

13. Esposito M. Sinus lift with guided boné regeneration or anorganic bovine boné: 1-year post-loading resultas of a pilot randomized clinical trial. Eur J Oral Implantol. 2010, 3(4):297-305.

14. Froum SJ. Sinus floor elevation using anorganic bovine bone matrix (OsteoGraf/N) with and without autogenous bone: a clinical, histologic, radiographic, and histomorphometric analysis - Part 2 of an ongoing prospective study. Int J Period Rest Dent. 1998, 18(6):528-43.

15. Froum SJ. Comparison of mineralized cancellous bone allograft (Puros) and anorganic bovine bone matrix (Bio-Oss) for sinus augmentation: histomorphometry at 26 to 32 weeks after grafting. Int J Period Rest Dent. 2006, 26(6):543-51.

16. Fugazzoto PA, Vlassis J. Long-term success of sinus augmentation using various surgical approaches and graftings materials. Int J Oral Maxillofac Implants. 1998, 13(1):52-7.

17. Galindo-Moreno P, Avila G, Fernández-Barbero JE, Aguilar M, Sánchez-Fernández E, Cutando A, Wang HL. Evaluation of sinus floor elevation using a composite bone graft mixture. Clin Oral Implants Res. 2007, 18(3):376-82.

18. Galindo-Moreno P. Histomorphometric comparison of maxillary pristine bone and composite bone graft biopsies obtained after sinus augmentation. Clin Oral Implants Res. 2010, 21(1):122-8.

19. Galindo-Moreno, P. Effect of anorganic bovine bone to autogenous cortical bone ratio upon bone remodeling patterns following maxillary sinus augmentation. Clin Oral Implants Res. 2011, 22(8):857-64.

20. Gapski R, Misch C, Stapleton D, Mullins S, Cobb C, Vansanthan A, Reissner M. Histological, histomorphometric, and radiographic evaluation of a sinus augmentation with a new bone allograft: a clinical case report. Implant Dent. 2008, 17(4):430-8.

21. Garg AK, Quiñones CR. Augmentation of the maxillary sinus: a surgical technique. Pract Periodontics Aesthet Dent. 1997, 9(2):211-9.

22. Garg AK. Augmentation grafting of the maxillary sinus for placement of dental implants: anatomy, physiology and procedures. Implant Dent. 1999, 8(1):36-46.

23. Geiger S, Pesh H. Animal and experimental studies of the healing around ceramic implants in bone lesion in the maxillary sinus region. Atsch Zahnärtzl Z. 1977, 32(5):37:396.

24. Gonshor A, McAllister BC, Wallace SS, Prasad H. Histologic and histomorphometric evaluation of an allograft stem cell- based matrix sinus augumentation procedure. Int J Oral Maxillofac Implants. 2011, 26:123-31.

25. Haas R, Baron M, Donath K, Zechner W, Watzek G. Porous hydroxiapatite for grafting the maxillary sinus: a comparative histomorphometric study in sheep. Int J Oral maxillofac Implants. 2002, 17(3):337-46. 
26. Hatano, N, Shimizy Y, Ooya K. A clinical long-term radiographic evaluation of graft height changes after maxillary sinus floor augmentation with a 2:1 autogenous bone/xenograft mixture and simultaneous placement of dental implants. Clin Oral Implants Res. 2004, 15(3):339-45.

27. He L, Chang X, Liu Y. Sinus floor elevation using osteotome technique without grafting materials: a 2-year retrospective study. Clin Oral Impl Res. 2011, 1:5.

28. Horowitz RA. The use of osteotomes for sinus augmentation at the time of implant placement. Compend Contin Educ Dent. 1997, 18(5):441-51.

29. Húrzeller MP. Reconstruction of severely resorbed maxilla with implants in the augmented maxillary sinus: 5 years clinical investigation. Int J Oral Maxillofac Implants. 1996, 11(4):466-75.

30. Iizuka T, Smolka W, Hallermann W, Mericske-Stern R. Extensive augmentation of the alveolar ridge using autogenous calvarial split bone grafts for dental rehabilitation. Clin Oral Implants Res. 2004, 15(5):607-15.

31. Jensen J, Sindet-Pedersen S, Oliver AJ. varyung treatment strategies for reconstruction of maxillary atrophy with implants: results in 98 patients. J Oral Maxillofac Surg. 1994, 52(3):210-6.

32. Jensen OT, Greer RO, Jr Johnson L, Kassebaum D. Vertical guided bone-graft augmentation in a new canine mandibular model. Int J Oral Maxillofac Implants. 1995, 10(3):335-44.

33. Jensen, T; Schou, S; Stavropoulos, A; Terheyden, H; Holmstrup, P. Maxillary sinus floor augmentation with Bio-Oss or Bio-Oss mixed with autogenous bone as graft in animals: a systematic review. Int J Oral Maxillofac Surg, 41(1):114-20, 2012.

34. Jensen, OT. Volumetric changes of the graft after maxillary sinus floor augmentation with Bio-Oss and autogenous bone in different ratios: a radiographic study in minipigs. Clin Oral Implants Res. 2012, 23(8):90210.

35. John HD, Wenz B. Histomorphometric analysis of natural bone mineral for maxillary sinus augmentation. Int $\mathbf{J}$ Oral Maxillofac Implants. 2004, 19(2):199-207.

36. Kahnberg KE, Rasmusson L, Zellin G. Bone Grafting Techniques for Maxillary Implants. 1st edn Denmark: Blackwell Munksgaard. 2005, 33-4.

37. Kaufman E. Maxillary sinus elevation surgery: an overview. J Esthet Restor Dent. 2003, 15(5):272-83.

38. Keller EE, Eckert SE, Tolman DE. Maxillary antral and nasal one-stage inlay composite bone graft: preliminary report on 30 recipient sites. J Oral Maxillofac Surg. 1994, 52(5):438-47.

39. Kent JN, Block MS. Simultaneous maxillary sinus floor bone grafting and placement of hydroxyapatite-coated implants. J Oral Maxillofac Surg. 1989, v.47.

40. Krennmair G, Krainhöfner M, Maier H, Weinländer M, Piehslinger E. Computerized tomography-assisted calculation of sinus augmentation volume. Int J Oral Maxillofac Implants. 2006, 21(6):907-13.

41. Lazzara RJ. The sinus elevation procedure in endosseous implant therapy. Curr Opin Periodontol. 1996, 3:17883.

42. Lee J, Susin C, Rodriguez NA, de Stefano J, Prasad HS, Buxton AN, Wikesjö UM. Sinus augmentation using rhBMP-2/ACS in a mini-pig model: relative efficacy of autogenous fresh particulate iliac bone grafts. Clin Oral Implants Res. 2012, 24(5):497-504.

43. Lee, YM, et al. Bone reaction to bovine hydroxyapatite for maxillary sinus floor augmentation: histologic results in humans. Int J Periodontics Restorative Dent. 2006, 26(5):471-81.

44. Lozada JL, Emanuelli S, James RA, Boskovic M, Lindsted K. Root-form implants placed in subantral grafted sites. J Calif Dent Assoc. 1993, 21(1):31-5.

45. Magini RS, Oliveira OMR, Vasconcellos DK. Acesso atraumático ao seio maxilar. In. MAGINI, RS et al. Enxerto Ósseo no Seio Maxilar: Estética e Função. São Paulo: Santos, 2006. p.185-217.

46. Marei MK, Saad MM, El-Ashwah AM, El-Backly RM, Al-Khodary MA. Experimental formation of periodontal structure around titanium implants utilizing bone marrow mesenchymal stem cells: a pilot study. Journal of Oral Implantology. 2009, 35(3):106-29.

47. Matos JDM, Santos IKS, Pereira ALC, Oliveira AJAG, Vasconcelos BCG, Neto ICP, Vasconcelos JEL. The use of the rich fibrin in platelets and leukocytes as alternative treatment for lifting the maxillary sinus - A Literature Review. International Journal of Development Research. 2017(07): 13436-13441.

48. Misch CE. Bone character: second vital implant criterion. Dent Today. 1988, 7:39-40.

49. Mordenfeld A. Histological and histomorphometrical analyses of biopsies harvested 11 years after maxillary sinus floor augmentation with deproteinized bovine and autogenous bone. Clin Oral Implants Res. 2010, 21(9):961-70.

50. Nevins M. The clinical and histologic efficacy of xenograft granules for maxillary sinus floor augmentation. Int J Periodontics Restorative Dent. 2011, 31(3):227-35. 
51. Orsini G, Traini T, Scarano A, Degidi M, Perrotti V, Piccirilli M, Piattelli A. Maxillary sinus augmentation with Bio-Oss particles: a light, scanning, and transmission electron microscopy study in man. J Biomed Mater Res B Appl Biomater. 2005, 74(1):448-57.

52. Özkan Y. Maxillary sinus floor augmentation using bovine bone grafts with simultaneous implant placement: a 5-year prospective follow-up study. Implant Dent. 2011, 20(6):455-9.

53. Ozyuvaci H, Bilgi B, Firatli E. Radiologic and histomorphometric evaluation of maxillary sinus grafting with alloplastic graft materials. J Periodontol. 2003, 74(6):909-15.

54. Piattelli, MA. Bone reactions to anorganic bovine bone (Bio-Oss) used in sinus augmentation procedures: a histologic long- term report of 20 cases in humans. Int J Oral \& Maxillofac Implants. 1999, 14(6):835-40.

55. Pikdöken L, Gürbüzer B, Küçükodacı Z, Urhan M, Barış E, Tezulaş E. Scintigraphic, histologic, and histomorphometric analyses of bovine bone mineral and autogenous bone mixture in sinus floor augmentation: a randomized controlled trial--results after 4 months of healing. J Oral Maxillofac Surg. 2011, 69(1):160-9.

56. Ribeiro FV. Peri-implant reconstruction using autologous periosteum- derived cells and guided boné regeneration. J Clin Periodontol. 2010, 37:1128-36.

57. Sauerbier S. Mesenchimal stem cells and bovine bone mineral in sinus lift procedures - an experimental study in sheep. Tissue Eng Part C Methods. 2010, 16(5):1033-9.

58. Srouji S, Ben-David D, Lotan R, Riminucci M, Livne E, Bianco P. The innate osteogenic potential of the maxillary sinus (Schneiderian) membrane: an ectopic tissue transplant model simulating sinus lifting. Int J Oral Maxillofac Surg. 2010,39(8):793-801.

59. Pikos MA. Buccolingual expansion of maxillary ridge. Dental Implantology Update. 1992, 3(11):85-7.

60. Raghoebar GM, Brouwer TJ, Reintsema H, Van Oort, RP. Augmentation of the maxillary sinus floor with autogenous bone for the placement of endosseous implants: a preliminary report. J Oral Maxillofac Surg. 1993, 51(11):1198-203.

61. Reiser GM. Evaluation of maxillary sinus membrane response following elevation with the cristal osteotome technique in human cadavers. Int J Oral Maxillofac Implants. 2001, 16(6):833-40.

62. Rissolo AR, Bennett J. Bone grafting and its essencial role in implant dentistry. Dental Clinics of North America. 1998, 42(1):91-115.

63. Rosen MD, Sarnat BG. Change of volume of the maxillary sinus of the dog after extraction of adjacent teeth. Oral Surg Oral Med Oral Pathol. 1995, 8:420-9.

64. Sakka S, Krenkel C. Simultaneous maxillary sinus lifting and implant placement with autogenous parietal bone graft: outcome of 17 cases. J Craniomaxillofac Surg. 2011, 39(3):187-91.

65. Santler G, Kaercher H, Gaggl A, Schultes G. Application of combined three-dimensional bone and soft tissue model. A case report. Int J Oral Maxillofac Surg. 1998, 27(6):482-4.

66. Sauerbier S, Stubbe K, Maglione M, Haberstroh J, Kuschnierz J, Oshima T, Xavier SP, Brunnberg L, Schmelzeisen R, Gutwald R. Mesenchymal stem cells and bovine bone mineral in sinus lift procedures - an experimental study in sheep. Tissue Eng Part C Methods. 2010, 16(5):1033-9.

67. Sbordone C, Sbordone L, Toti P, Martuscelli R, Califano L, Guidetti F. Volume changes of grafted autogenous bone in sinus augmentation procedure. J Oral Maxillofac Surg.2011, 69(6):1633-41.

68. Schwartz-Arad D, Herzberg R, Dolev E. The prevalence of surgical complications of the sinus graft procedure and their impact on implant survival. J Periodontol. 2004, 75(4):511-6.

69. Sicca CM. Comparative histomorphometric and tomographic analysis of maxillary sinus floor augmentation in rabbits using autografts and xenografts.J Biomed Mater Res B Appl Biomater. 2008, 86(1):188-96.

70. Small SA, Zinner ID, Panno FV, Shapiro HJ, Stein JI. Augmenting the maxillary sinus for implants: report of 27 patients. Int J Oral Maxillofac Implants. 1993, 8(5):523-8.

71. Smiler DG, Holmes RE. Sinus lift procedure using porous hydroxyapatite: a preliminary clinical report. J Oral Implantol. 1987, 13(2):239-53.

72. Soltan M, Smiler DG. Antral membrane balloon elevation. J Oral Implantol. 2005, 31(2):85-90.

73. Summers RB. A new concept in maxillary implant surgery: the osteotome technique. Compend Contin Educ Dent. 1994, 15(2):152-60.

74. Summers RB. The osteotome technique: part 4 - Future site development. Compend Contin Educ Dent. 1995, 16(11):1090-8.

75. Tatum H Jr. Maxillary and sinus implant reconstructions. Dent Clin North Am. 1986, 30:207-29.

76. Tidwell JK, Blijdorp PA, Stoelinga PJ, Brouns JB, Hinderks F. Composite grafting of the maxillary sinus for placement of endosteal implants. A preliminary report of 48 patients. Int J Oral Maxillofac Surg. 1992,21(4):204-9. 
77. Timmenga NM, Raghoebar GM, Boering G, van Weissenbruch R. Maxillary sinus function after sinus lifts for the insertion of dental implants. J Oral maxillofac Surg. 1997, 55(9):936-9.

78. Timmenga NM, Raghoebar GM, van Weissenbruch R, Vissink A. Clin Oral Implants Res. 2003, 14(3):322-8.

79. Van den Bergh JP, ten Bruggenkate CM, Krekeler G, Tuinzing DB. Sinusfloor elevation and grafting with autogenous iliac crest bone. Clin Oral Implants Res. 1998, 9(6):429-35.

80. Traini T. A histologic and histomorphometric evaluation of anorganic bovine bone retrieved 9 years after a sinus augmentation procedure. J Periodontol. 2007, 78(5):955-61.

81. Wallace SS, Froum SJ, Tarnow DP. Histologic evaluation of a sinus elevation procedure: a clinical report. Int J Periodontics Restorative Dent. 1996, 16(1):46-51.

82. Wallace SS, Froum SJ, Cho SC, Elian N, Monteiro D, Kim BS, Tarnow DP. Sinus augmentation utilizing anorganic bovine bone (Bio-Oss) with absorbable and nonabsorbable membranes placed over the lateral window: histomorphometric and clinical analyses. Int J Periodontics Restorative Dent. 2005, 25(6):551-9.

83. Woo I, Le BT. Maxillary sinus floor elevation: review of anatomy and techniques. Implant Dent. 2004, 13(1): 28-32.

84. Wood RM, Moore DL. Grafting of the maxillary sinus with intraorally harvested autogenous bone prior to implant placement. Int J Oral Maxillofac Implants. 1988, 3(3):209-14.

85. Zijderveld SA, Zerbo IR, Van DenBergh JP, Schulten EA, ten Bruggenkate CM. Maxillary sinus floor augmentation using a beta-tricalcium phosphate (Cerasorb) alone compared to autogenous bone grafts. J Oral Maxillofac Implants. 2005, 20:432-40.

86. Zizelmann C, Schoen R, Metzger MC, Schmelzeisen R, Schramm A, Dorr B, Bormann KH, Gellrich NC. Bone formation after sinus augmentation with engineered bone. Clin Oral Impl Res. 2007, 18:69-73. 